\title{
Leaders' attitudes towards, and commitment to quality management of training within the military
}

\author{
Renier Christiaan Els and Helen H.W. Meyer \\ Global Innovative Forefront Talent (GIFT) Niche Area, \\ Faculty of Economic and Management Sciences, North-West University, \\ Potchefstroom, South Africa
}

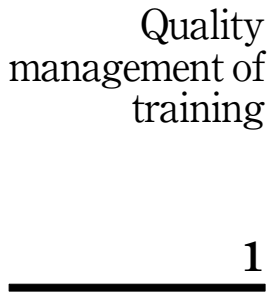

Received 8 September 2021 Revised 30 November 2021 Accepted 13 December 2021

\begin{abstract}
Purpose - The successful implementation of quality management in organizations is dependent on people, particularly leaders. It seems as if leaders' affective states (attitudes and commitment) in the military were connected to their capability to inspire people and a group (corps training unit) to achieve a common goal. The research reported in this article was aimed at examining officers in corps training units' attitudes towards, and commitment to quality management in training in the South African Army.

Design/methodology/approach - Focus group interviews were conducted with a sample of 49 officers on various levels (senior, junior and warrant officers) at six South African Army corps training units.

Findings - The findings indicate that the attitudes of leaders played a significant role to ensure that quality management of training is conducted effectively. Participants experienced that leaders in the South African Army were mostly responsible for the negative attitudes of officers in corps training units. Inadequate leadership support and lack of trust contributed to a lack of transparency and poor communication that resulted in poor commitment among officers at corps training units. The investigation further revealed that a positive affective state (attitudes and commitment) of leaders is essential in ensuring effective quality management of training.

Originality/value - The potential usefulness of this research may provide insight into how leaders' affective state could be improved to ensure effective quality management. This research may also be of interest to other organizations that conduct in-house training.
\end{abstract}

Keywords Quality management, Training, Systems theory, Total quality management, Leaders, Attitudes, Commitment, Military

Paper type Research paper

\section{Introduction}

For organizations to be effective, they require effective leaders to enable them to remain competitive with the ability to respond to the challenges and complexities faced by their own environments (Aramovich and Blankenship, 2020; Wallace et al., 2021). In addition, leaders' roles and impact stretch beyond that of their organizations, to society (Kosfeld, 2020). Leaders are required to guide personnel to devotedly agree to follow them and expand their effort towards the achievement of their organisation's mission and objectives (Kirchner and Akdere, 2014; Boulu-Reshef et al., 2020; Eisenkopf, 2020). The success of quality management

(C) Renier Christiaan Els and Helen H.W. Meyer. Published by Emerald Publishing Limited. This article is published under the Creative Commons Attribution (CC BY 4.0) license. Anyone may reproduce, distribute, translate and create derivative works of this article (for both commercial and non-commercial purposes), subject to full attribution to the original publication and authors. The full terms of this license may be seen at http://creativecommons.org/licences/by/4.0/legalcode

The authors wish to acknowledge GIFT Research Unit (Global, Innovative, Forefront, Talent Management Research Unit) for the funding to publish the article open access.

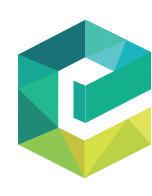

The TQM Journal Vol. 34 No. 7, 2022 Emerald Publishing Limited 1754-2731 DOI 10.1108/TQM-09-2021-0259 
TQM

34,7

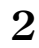

(QM) starts with the top management of an organisation (Javed, 2015). Apart from top management, leaders on all levels (top, middle and supervisory) are considered core (McCauley and Palus, 2021) and for the successful implementation of QM (Chen, 2012). Therefore, leaders at all levels should take ownership of quality. QM signifies going beyond the customer's expectations, while at the same time developing and maintaining organisational capability to continually improve quality (Meyer et al., 2017). Quality should be promoted, and QM emphasized by organizations, to ensure that organizations remain competitive (Jamaluddin et al., 2015).

Training refers to the development of skills concerning employees' jobs, with the aim of bringing about improvement in job performance (Meyer, 2016). Training is linked to QM, as both involve continuous improvement. Training is also considered essential to promote a quality culture (for example to embed the quality values in personnel) that is necessary to maintain QM standards (Shabbir et al., 2016). Training improves the skills of personnel, thereby also contributing towards the continuous improvement of QM systems. Within the context of QM, training could therefore be regarded as a planned and continuous event.

Previous research in the military by authors such as Boe (2015) (Norway) examined aspects of leadership and management competence, while Wong et al. (2018) (Malaysia) investigated the relationship between QM dimensions and sustainable performance. Therefore, it is evident that research regarding QM in the military has so far mainly focused on employees (leaders in particular) and their ability to ensure quality. Three studies, conducted in the United States (Porter et al., 1974; Harrison et al., 2006) and Sri Lanka (Mathew and Zacharias, 2016), quantitatively measured the attitudes of employees and the relationship of attitudes with organisational commitment. Chowdhury et al. (2007) (Thailand) also quantitatively measured specifically the impact of top management's commitment on total quality management (TQM), which may point to the fundamental role that leaders' attitudes (mind-set) fulfil in influencing commitment (favourably or unfavourably) to a cause. Vogel et al. (2021), however, found that most leadership studies focused on cognitive-related theories, instead of affect-related theories. McCauley and Palus (2021) argued that most studies focused on changing leaders' behaviours, instead of addressing underlying mindsets, which are often the main cause of problematic behaviours. For example, a recent quantitative study conducted by Els et al. (2021) in the South African military found that leaders' attitudes had a significant influence on their commitment to QM of training (Els et al., 2021). Previous research in QM of training in South Africa mainly focused on the needs to develop human resources to improve QM. Nhlapo (2010) examined the way in which human resources are developed to emphasize human resource development (HRD) strategies to improve total quality management (TQM) in the correctional services department. However, no evidence could be found of studies that qualitatively explored leaders' mindsets (attitudes) and commitment to the QM of training. Vogel et al. (2021) also expressed a need for more qualitative methodologies to appreciate the "in-depth interactions in and with organizations". It is therefore evident that more qualitative research is needed to explore the role of leaders' attitudes and commitment in QM of training.

The research reported in this article explored officers' experiences concerning the attitudes towards and commitment of other leaders in the South African (SA) Army to QM of training.

The following research question guided the research:

$R Q 1$. How do officers at corps training units experience the attitudes and commitment of other leaders in the SA Army to QM of training?

A qualitative research design, specifically a case study, was used to answer the research question. The article is structured as follows: The conceptual and theoretical framework that underpins the research will be discussed before the empirical investigation. Thereafter, the 
findings will be presented and then discussed followed by implications for theory and practice with recommendations. Lastly, a conclusion will be provided to wrap up the key thoughts concerning leaders' attitudes and commitment to QM of training in the military. This article contributes to scant research on QM of training within a military context. Therefore, this research may make a theoretical and practical contribution concerning the influence of leaders' attitudes on their commitment to QM of training within a military context. Insights obtained from this article may enhance the current understanding and are anticipated to extend the efforts of leaders in the SA Army to address the affective state (attitudes and commitment) of leaders with respect to QM of training.

\section{Conceptual and theoretical framework}

The investigation concentrated on QM of training in the SA Army (the SA Army is part of the South African National Defence Force), specifically the management of the quality of training within a military context. The SA Army's core business is that of force preparation; in other words, training (Gildenhuys, 2013, p. 14). The SA Army forms part of the armed forces (defence force of a country), together with the air force, navy and the medical service. An army refers to a ground force that fights primarily on land (Wessels, 2013, p. 242) and protects society against insurgencies from outside the borders of SA.

There are different corps training units in the SA Army that are responsible for the training and development of high-quality soldiers to defend the country on land. A corps training unit is also the place where training activities are planned and implemented (Shenge, 2014). This research was undertaken in six of these corps training units in the SA Army.

Officers within these corps training units are leaders as they have the responsibility to ensure that quality training is planned, developed and implemented to imbue the soldiers with the required knowledge and skills (QM). More specifically, and in this research, leaders included rank-bearing officers (senior, junior and warrant) who were responsible for the management and guiding of their corps training units towards high quality training. This research therefore focused on these officers (leaders) at corps training units' experiences of other officers and leaders' attitudes and commitment to QM of training in the SA Army.

Analysis of the Defence Review 2015, the DoD strategic plan, the HR charter 2020, and an environmental analysis regarding the training and education environment of the Department of Defence (DoD), including the SA Army corps training units, revealed that leaders in the South African National Defence Force (SANDF) were unable to meet the aims towards improving the quality management system, and that leadership development required attention (South African Department of Defence, 2016). Carrington et al. (2019) argued that leaders are required to deal with continuous challenges to ensure that their environments can adapt appropriately; therefore, the development of leaders in organizations requires cognitive shifts to prevent disinterest. Regardless, leaders' inability to meet the aims to improve QM of training may also be linked to their attitudes and commitment to QM of training, and this may lead to the inadequate implementation of QM in the training of their subordinates, i.e. the soldiers on the ground. If soldiers do not receive quality training, they may not acquire the critical skills required to protect and defend SA and its citizens on land, which will endanger the security of the country. Consequently, society will not be protected, and it will also result in negative attitudes from the public. Therefore, the focus of this research was on leaders' attitudes towards and commitment to QM of training.

\subsection{Attitudes and commitment}

"Attitudes" affect behaviour, and how things and other people are perceived (mind-set) (Majid et al., 2019). Consequently, the attitudes of leaders in this research could be linked to the positive or negative mind-set of officers concerning QM of training in the SA Army corps 
TQM

34,7

4

training units. Ehrhardt et al. (2011) indicated that commitment can be the degree to which an individual views (perceptions) or ascribes (attitudes/feel) to something. Commitment, therefore, can be regarded as an attitude, behaviour or as a binding force (Batista et al., 2013). Consequently, in the case of this research, the commitment of officers in corps training units could be affected by leaders' attitudes in the SA Army that may be enacted as either good or poor commitment (behaviour) to QM of training.

For leaders to execute QM effectively, and involve personnel with continuous improvement, they will need to apply the QM principles (customer focus, leadership commitment, people-involvement, supplier quality, quality culture, continuous improvement and fact-based decision-making) (Luburic, 2015). However, only leadership commitment and people involvement will be discussed, because these two principles relate to the affective side (the focus of this research) required by personnel (officers) to effectively manage the quality in training.

\subsection{Leadership commitment}

Leaders are required to led by example (Eisenkopf, 2020), and therefore they should demonstrate their commitment and support to QM through their actions - this is also an indication that they are indeed serious about QM (Wong et al., 2018). Leadership commitment is demonstrated when leaders prioritize both the resources required and continuous improvement [for example resources required for QM of training] (Talib and Rahman, 2015; Hall et al., 2018). Leadership commitment consists of both cognitive and affective components (West and Cianfrani, 2014). Some studies conducted on commitment by leaders emphasize the affective state/component (West and Cianfrani, 2014; Luburic, 2015; Els et al., 2021). The affective state/component of leadership commitment therefore also includes leaders' attitudes. On the other hand, leaders' attitudes may also be indicative of their commitment to $\mathrm{QM}$ of training.

\subsection{People involvement}

Leadership commitment and people involvement are integrated and drive one another to ensure continuous improvement (West and Cianfrani, 2014; Luburic, 2015). People involvement entails the empowerment and development of people to deliver quality products or services (Wong et al., 2018). People involvement assists organizations to identify constraints to personnel's performance. By identifying constraints in performance, personnel are more inclined to actively seek opportunities to enhance their own competence, knowledge and experience (Wong et al., 2018) by fostering autonomy and self-responsibilities (Cheong et al., 2016; Neubert et al., 2016). According to Cheong et al. (2016), leadership literature has consistently recognised the role of leaders to influence the empowerment of people. Therefore, leaders should ensure that soldiers are involved in quality, identify constraints in performance related to quality and develop (empower) people to ensure the delivery of quality services (by the SA Army).

\subsection{Theoretical framework: systems theory}

QM refers to a cross-functional practice and takes place between departments within an organization (Nguyen et al., 2018). Originally, QM emphasized a process-oriented workflow (including process management, product and service design for quality, quality-related problem-solving and training, quality data reporting and continuous improvement). Due to the increased complexity of entities (i.e. customers, suppliers, different departments) and their constant interaction, a paradigm shift was made from a process-oriented to a system's view (Weckenmann et al., 2015). Therefore, QM ought to be managed as part of an integrated 
organizational system to deal with an ever-changing (dynamic) environment. Leadership

literature also increasingly refers to collective approaches to understand leadership as part of an organisational system that consists of teams, networks and departments (McCauley and Palus, 2021). Tsui et al. (2006) also alluded to a link between leadership behaviour [commitment] and organisational culture. The systems theory provides a foundation for understanding the phenomenon under study.

The systems theory offers a collection of elements concerned with the performance of the whole, which is affected by each one of its parts (Ju, 2019). A system consists of inputs, processes, outputs and feedback that are in a constant feedback loop (Ju, 2019). Within a QM of training context, for example, the inputs refer to resources (human, finances, customer needs) and/or consistencies or inconsistencies (knowledge obtained from defects identified in the QM system) identified from feedback. The process (quality assurance and quality control, among other) refers to corrective measures taken to correct inconsistencies identified within QM processes. The outputs are high quality products or services [such as training] gained from adequate processes, and the feedback refers to consistencies and/or inconsistencies detected in processes and outcomes. This should be a continuous cycle starting with input to feedback - the feedback also serves as input in the continuous cycle $(\mathrm{Ju}, 2019)$. The systems theory also relates to the context of the SA Army; as a system, it consists of different levels or subsystems that affect each other and are mutually interdependent. If leaders in the SA Army make inadequate decisions concerning $\mathrm{QM}$ within training, these decisions may adversely affect the quality of training in corps training units to the lowest level.

All organizations, either manufacturing or those delivering services (such as training), need to apply QM principles. Based on the systems theory, the QM principles are mutually interdependent and strengthen and support one another. Accordingly, leaders should demonstrate leadership commitment to QM by providing the required resources (inputs) and support to ensure quality products and services (outputs). Leadership commitment should also be linked with people involvement to ensure continuous improvement and a quality culture. Finally, QM of training should be understood as a process of continuous improvement driven by officers through people involvement (soldiers) to allow personnel (soldiers) to take co-responsibility for quality at all levels within the SA Army system. The abovementioned theory was tested in practice by means of an empirical investigation that will be described in the next section.

\section{Empirical investigation}

\subsection{Aim of the investigation}

The aim of this investigation was to determine how participants (officers) made sense of their own environment (corps training units in the SA Army) based on their own experiences concerning leaders' attitudes and commitment to QM of training.

\subsection{Research design}

Due to the exploratory nature of this research, a qualitative research design was adopted. Qualitative research was used to obtain rich and thick data by focusing on participants' experiences of leaders' attitudes, and commitment to QM of training, as suggested by Nieuwenhuis (2016).

\subsection{Research strategy}

A case study research strategy was used for this investigation. In this research, the case study allowed for a detailed understanding of leaders' attitudes, and commitment to QM of training within corps training units in the SA Army, as suggested by Nieuwenhuis (2016). 
TQM

34,7

6

\subsection{Research method}

An interview schedule that focused on factors that may have affected leaders' attitudes and commitment to QM of training in corps training units was used. Focus group interviews were used to generate rich and detailed data, which would have been difficult to generate through other research methods (such as a survey), as suggested by Nieuwenhuis (2016). Corps training units are dispersed geographically all over SA. The researcher had to travel to each of these corps training units and could only spend one day, maximum, at each corps training unit to generate data. Focus group interviews were therefore the most viable option to generate data, since a group of participants (five to nine) could be interviewed at once and within the one day available, before the researcher had to travel to the next corps training unit.

3.4.1 Study population. The study population consisted of all officers (senior, junior and warrant) in six of the eight corps training units in the SA Army. The six corps training units were selected since that they had been entrusted with specific duties (infantry, anti-air defence artillery, artillery, armour, engineering, and tactical intelligence) in the SA Army. The focus of the other corps training units in the SA Army was different from the six selected corps training units in terms of their duties, which were more support services (i.e. human resources, culinary and logistical support) and preparation for career responsibilities (leader training and SA Army promotional training programmes), and therefore they provided different types of training. They were, therefore, excluded from this research.

3.4.2 Sampling. Purposeful sampling was used to select participants for six focus groups. Purposeful sampling was used to target officers who were responsible for the management of training in corps training units. In this research, officers in corps training units in the SA Army who had met the following criteria were selected: (1) the participants must have adequate knowledge and experience (minimum 2 years) regarding QM of training to effectively answer the research question and make a meaningful contribution to the research; (2) should have been officers (senior, junior and warrant) involved in training within corps training units since they play a critical role in the effective implementation of QM in training. Each of these focus groups contained between seven and nine participants. In total, 49 participants voluntarily participated in these interviews. Table 1 contains the profile of participants. It may be concluded from Table 1 that a large qualitative sample $(N=49)$, as suggested by Creswell and Creswell (2018), to minimize validity threats, was selected. The qualitative sample was diverse, consisting of different race groups and both men and women and is therefore representative of the study population.

\begin{tabular}{|c|c|c|c|c|c|c|c|c|}
\hline $\begin{array}{l}\text { Corps } \\
\text { training unit }\end{array}$ & $\begin{array}{l}\text { Senior } \\
\text { officers }\end{array}$ & $\begin{array}{l}\text { Junior } \\
\text { officers }\end{array}$ & $\begin{array}{l}\text { Warrant } \\
\text { officers }\end{array}$ & Black & White & Men & Women & $\begin{array}{l}\text { Total sample } \\
\text { per corps } \\
\text { training unit }\end{array}$ \\
\hline
\end{tabular}

Table 1.

Profile of participants' demographic information

A
B
C
D

E 3

$\mathrm{F}$

$n=49$

Percentage

3

$2-2$

3

$3 \quad 3$

3

2

$16 \quad 16$

$33 \% \quad 33 \%$

\begin{tabular}{|c|c|c|}
\hline 3 & 9 & 0 \\
\hline 3 & 6 & 1 \\
\hline 2 & 5 & 3 \\
\hline 3 & 5 & 4 \\
\hline 3 & 6 & 3 \\
\hline 3 & 5 & 2 \\
\hline 17 & 36 & 13 \\
\hline $35 \%$ & $73 \%$ & $27 \%$ \\
\hline
\end{tabular}

$\begin{array}{rrr}5 & 4 & 9 \\ 6 & 1 & 7 \\ 7 & 1 & 8 \\ 7 & 2 & 9 \\ 9 & 0 & 9 \\ 5 & 2 & 7 \\ 39 & 10 & \\ 80 \% & 20 \% & \end{array}$


3.4.3 Ethical clearance. Ethical clearance was obtained from the university, and written permission from the Department of Defence Intelligence and Chief of the SA Army were obtained. Consent was obtained from participants by means of letters of consent. Transcriptions and video recordings were password protected on the computer used and were also locked and stored away in a safe to ensure confidentiality. Names of participants and places (corps training units) were replaced with neutral identifiers on all transcriptions and reports to ensure anonymity.

3.4.4 Trustworthiness. To ensure trustworthiness and credibility, peer scrutiny and crosschecking were employed, as suggested by Creswell and Creswell (2018). To ensure credibility, all aspects of the collection, analyses, and interpretation of data were discussed and scrutinized with peers. An audit trail by means of field notes, transcriptions, and video recordings concerning each step of the research was kept, providing for the possibility of data to be reanalysed if required. This allows an outsider to audit the whole research process, if requested.

3.4.5 Data generation. Focus group interviews were used to generate qualitative data to answer the research questions. The focus group interviews held at each corps training unit were recorded by means of video/digital recording. Video recordings also assisted in the identification of group members [biographical information] during data transcribing, as indicated by Nieuwenhuis (2016). These interviews lasted between 45 and 60 min on average. Focus group interview questions ranged from general questions to more specific questions regarding the QM of training to elicit participants' general experiences around this. Participants were eased into the process of active debate where questions then became narrower and more structured, as suggested by Nieuwenhuis (2016).

Observations were anticipated to enhance descriptions provided by participants, creating a clearer understanding concerning the phenomenon under study, as suggested by Anderson et al. (2020). During the interviews, it was observed that at all the corps training units (A, B, C, D, E, F) it seemed that when a participant explained something scrupulously (this happened in most cases), they expressed their helplessness, and as a result frustration. Therefore, participants (officers at corps training units) may have realised that nothing could be done to resolve the issues identified by them, which may have also resulted in not trusting their superiors. This was evident in the frustration expressed by these participants as they must deal with this daily. It was also observed that some participants' non-verbal language (shaking of head and facial expressions) concerning the ignorance of leaders at higher headquarters resulted in frustration, which made it difficult to implement QM effectively. During the interviews, it was also observed that most participants from corps training units seemed to agree that personnel (officers) involved with QM of training were not adequately qualified (competent) to fill positions (key training positions), and therefore some hesitance was noted. Interestingly, linked with competent leaders, it was observed specifically that black participants mentioned that the implementation of affirmative action resulted in poor relationships with other leaders from the SA Army and within the corps training units and negatively affected the $\mathrm{QM}$ of training.

3.4.6 Data analysis. To analyse the focus group interview data, a five-step qualitative data analysis process was applied, as suggested by Creswell and Creswell (2018). The method that was utilised to analyse the data was the constant comparative method. The analysis of data also involved making sense of both text and image data (transcriptions and video recording). Codes and categories were examined by means of a three-stage process. Firstly, open coding, which involved going through the data, examining, and comparing all the different parts to generate categories, as suggested by Thomas (2016), was applied. Temporary categories were highlighted by coloured markers. Axial coding assisted in making sense of open coding, fitting these ideas together, and determining how they are connected to label these codes. Selective coding then helped to determine where the main themes were drawn, to select the core categories and to systematically relate it to other categories, as suggested by Nieuwenhuis 
TQM

34,7

8

(2016). Relationships of themes and categories were validated, refined and developed to organise data that fit together for a preliminary analysis. If necessary, the existing data were recoded. The findings that emanated from the empirical investigation are presented in the next section.

\section{Findings}

In this section, the experiences of officers in corps training units are presented with a particular focus on the affective state (attitudes and commitment of leaders) and the affect thereof on QM of training in corps training units.

The findings are presented according to the major themes that emerged and only the most appropriate direct verbatim quotes will be provided to support a finding. Four main themes and nine subthemes emerged from the data analysis.

\subsection{Leaders' attitudes that adversely affect focus}

Within the context of this research, most participants indicated that leaders in the SA Army do not have adequate attitudes towards QM in training. It emerged that leaders in the SA Army are not focused and this adversely affected acknowledgment of focused ideas in corps training units to improve quality.

4.1.1 Lack of resources creates frustration. In three corps training units (A, B and C), participants felt that they were not receiving adequate support from their leaders at corps training units and other leaders in the SA Army. As a result, adequate resources were not available when needed for already planned training interventions. Participants felt burdened by the scheduling of extra courses by leaders at SA Army level; additionally, this creates a burden for subordinates. One participant (senior officer) expressed this as follows:

... because now you have a course with eight members [personnel] on the course and then two months' later management inform us oh there were supposed to be 20 members [personnel] on this course, so scheduled an ad hoc course for the rest of the members [personnel] and that course was not planned, and resources are already a problem.

4.1.2 Lack of enthusiasm. Participants indicated that other leaders at the various corps training units lack enthusiasm concerning QM within training. One participant (senior officer) from corps training unit $\mathrm{C}$ verbalised it as follows:

Concerning enthusiasm at top level [SA Army], it is not there or top management [leaders at corps training unit] in the unit ...

A participant (warrant officer) from another corps training unit (D) added that other leaders are not enthusiastic about training and the quality thereof. This participant felt that it may be because leaders being utilised within their corps training unit do not necessarily want to be in training. Therefore, this participant links enthusiasm with everyone's own objectives. This was articulated as follows:

Leaders do not have enthusiasm; for example, he is a very good trainer of a trainer but he is not utilised in that environment so that is why I am saying that enthusiasm is different from all because we are chasing different objectives.

\subsection{Leaders' attitudes that affect prioritizing quality management in training}

Participants indicated that other leaders in the SA Army tend to be resistant to change and lack passion, which make quality improvement in training difficult. Therefore, participants felt that leaders then may tend to position QM of training low on the priority agenda, which, in turn, impacts QM of training negatively.

4.2.1 Resistance to change. In corps training unit A, one participant (senior officer) indicated that other leaders (officers) in the corps training units and at the SA Army find it 
difficult to change the status quo (how everybody has done it for a long time). Additionally, these participants indicated that change takes time. This was confirmed by nine officers, and was expressed by one junior officer from corps training unit B as follows:

Leaders in this unit are not open to change, the unit as a whole is very resistant to any type of change, any new idea ...

4.2.2 Lack of passion. Participants within the context of this research indicated that other leaders in the corps training units do not demonstrate passion. This was confirmed by seven officers. A warrant officer from corps training unit B articulated it as follows:

Regarding the passion of leaders, this is what I have seen, the leaders do not have passion any more ...

Participants from corps training units $\mathrm{C}$ and $\mathrm{D}$ indicated that leaders at the corps training units' authority to be exposed to QM within training was taken away, which made it difficult to remain passionate. It was expressed by one senior officer as follows:

Leaders in this unit do not demonstrate passion because in terms of my peers' authority is taken away from many of us, and a lot of us, me included we are not exposed to QM ...

\subsection{Experiences concerning leadership that adversely affect leaders' commitment}

4.3.1 Lack of support. Thirteen participants felt that leaders in the SA Army do not demonstrate the necessary support. This resulted therein that personnel became demotivated, also negatively affecting the quality of training. One senior officer from corps training unit B expressed this as:

... it contributes negatively towards reaching organisational objectives and this impacts the quality of training negatively as there is then no support regarding training for training wings and branches in the unit.

4.3.2 Lack of competence. Participants felt that leaders in the SA Army and corps training units lack the necessary knowledge, skills and attitudes concerning QM in training.

Eighteen participants felt that leaders in the SA Army also do not organise the use of resources (funds) properly, which makes training difficult. Furthermore, participants indicated that leaders at corps training unit level do not demonstrate the necessary knowledge and experience to drive quality. This was expressed by a senior and then a warrant officer as follows:

... for me adequate availability of money is there, when the treasury gives out the money to the Defence, the chief army distribute the money accordingly, so the units need to manage their funds properly.

Leaders in this unit does not have the necessary knowledge and experience to drive QM of training.

Some participants indicated that transformation (affirmative action) has been managed poorly when it came to staffing and promotion of SA Army personnel, and therefore has a negative impact on QM of training. Furthermore, these participants indicated that personnel placed in certain positions do not necessarily have the qualifications to ensure effective QM of training. This was expressed by a senior officer as follows:

... both affirmative action and the change, because this thing involves the post, as this thing cannot be hold by this person or by this one and the person who should actually hold the post is having the qualification and can do the job, but because of this affirmative action he cannot have that post...

4.3.3 Lack of people involvement. Participants from corps training units' $\mathrm{C}$ and $\mathrm{D}$ indicated that leaders do not involve all personnel in $\mathrm{QM}$ of training. A participant (senior officer) verbalised it as follows:

Leaders in the unit [corps training unit] are not committed to involve all people to the lowest level regarding $\mathrm{QM}$ of training ... 

demonstrate commitment, which has resulted in the development of a lack of trust. Additionally, a key contributing factor included negative attitudes towards QM of training. One participant (warrant officer) in corps training unit D verbalised it as follows: "The colonel says he does not trust us, he said I do not trust you to all the instructors, so do you think I trust him if he does not trust me".

4.4.1 Lack of trust. In corps training units' B and C, participants felt that they do not trust leaders in the SA Army for various reasons, such as leaders are not qualified in training, if trust is not present then mentoring and coaching become difficult, and not all leaders demonstrate an honest attitude to assist subordinates. This makes the execution of tasks (QM of training) difficult. One participant (senior officer) verbalised it as follows:

... one of the things that I have seen in that document is the issue of mentoring and coaching, so if there is no trust, whether formal or informal mentoring and coaching will not happen ... so if there is no trust there will not be a transfer of knowledge and skills.

Another participant (a senior officer) from corps training unit $\mathrm{E}$ felt that communication plays an important role in establishing trust. This was verbalised as follows:

Here with regard to trust between leaders and subordinates I have to bring in communication, if communication is bad, the message does not get through and that creates a lack of trust which sometimes happens in our unit.

Some participants indicated that the bureaucracy within the SA Army at higher levels and the corps training units has an adverse effect on QM of training. Participants felt that leaders at corps training units find it difficult to trust higher level leaders with problems and that also makes mentoring difficult. One senior officer verbalised it as follows:

I must be able to come to you with problems that I am facing at lower level, then I am expecting you to understand. This also makes mentoring difficult which also influences the trust between leaders.

Two participants, from corps training units $\mathrm{E}$ and $\mathrm{F}$, felt that bureaucracy creates frustration as it delays decisions to be made concerning the quality of training. The same participants (junior officers) explained that leaders at corps training units who are aware of the problems should be trusted to make decisions:

... leaders in this organisation views the bureaucratic structure superior to ensuring QM, you know administration and bureaucracy will always take priority over everything else ...

... why can't they get the authority to cancel that course, that extends the decision-making time and reaction time ... this is where the formation [higher headquarters] needs to give the school authority to do certain things, this also reverts to trust.

4.4.2 Poor attitude leads to a lack of commitment. In corps training units B, D and E, eight participants felt that other leaders in corps training units do not demonstrate passion for QM of training, which they also linked to poor attitudes, which, in turn, affects commitment. This, in turn, creates a poor attitude among leaders at corps training units, thereby affecting the QM of training adversely. This was expressed by one participant (a senior officer) as follows:

In my own unit it comes back to passion and attitude, if I lost my passion then my attitude is going to become negative and if my attitude is negative, I am not going to have any commitment at all, I think those things are directly related to each other.

In the next section, a discussion of the findings in terms of the conceptual and theoretical framework will be done. 


\section{Discussion}

In this section, a discussion will follow concerning the key findings in terms of the conceptual and theoretical framework concerning leaders' attitudes and commitment.

\subsection{Leaders' attitudes that affect QM of training adversely}

Leaders in the SA Army's negative attitudes can be explained by the systems theory whereby organisational frustrations (within larger system of SA Army) such as resources (provided by leaders from corps level) and the environment (SA Army) discouraged leaders at the lowest level (at corps training unit (sub-systems)) to sustain high quality training. In addition, organisational aspects such as lack of resources, lack of enthusiasm, resistance to change by leaders at higher levels (SA Army) and lack of passion created frustrations for leaders at corps training units and adversely influenced $\mathrm{QM}$ of training. If officers at corps training units do not have the adequate resources to put into the quality of training, it results therein that these officers lose their enthusiasm and passion. Consequently, the QM processes will become problematic, which may lead to poor quality training with no feedback loop to improve on the QM system. Poor attitudes of officers at corps training units also resulted from the lack of focus demonstrated by their leaders at SA Army level and may indicate a system's problem. The lack of focus and enthusiasm experienced by officers may also be because of poor communication from other officers at the SA Army. These findings were expected, because the findings also revealed that a lack of resources created frustrations, which had an adverse effect on QM of training to the lowest level in the system. A similar finding was previously reported by Mosadeghrad (2015) that when resources are not included as part of the strategic quality plan, it may create difficulty to identify requirements to achieve QM goals.

Leaders from the SA Army's resistance to change concerning the quality of training may have created a sense of not prioritising QM of training. Officers at corps training units experienced a feeling of detachment due to their suggestions (for improvement of QM) being resisted by senior leaders at the SA Army and other leaders at corps training units, and this adversely affected the QM of training. Additionally, the findings of officers' resistance to change may also point towards an inadequate organisational culture in the SA Army and per implication within corps training units. This finding may support findings from previous research (Talib et al., 2011; Talib and Rahman, 2015) conducted in relation to the effect of organisational cultures on QM implementation. In addition, previous leadership research (Tsui et al., 2006) found that the powerful role that leaders play in shaping the organisational culture should not be disregarded. However, of interest is that previous findings did not indicate a lack of enthusiasm and passion as contributing factors to an inadequate organisational culture. These findings may be due to the (military) context, and further research into the effect of these aspects on organisational culture could also be conducted within other contexts to support these findings. Vogel et al. (2021) also recently alluded to organisational context that may influence leadership behaviour. As this research was conducted within a military context, the finding cannot be generalised (prior to similar research within other contexts).

\subsection{Leaders' lack of commitment that adversely affect QM of training}

Another key finding in this research that emerged was that officers in corps training units experienced a lack of commitment from other leaders in the SA Army and corps training units as part of a system to QM of training. Officers at corps training units experienced a lack of support from leaders in the SA Army. The lack of support from leaders in the SA Army may also be due to the lack of resources provided (experienced as frustration as part of attitudes) to officers at corps training units that discouraged them to implement QM effectively. This finding aligns with previous research that similarly found that it is a critical characteristic of leaders to be able to establish a culture of support, though within a different context (financial

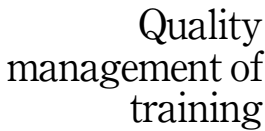


TQM

34,7

services) (Hall et al., 2018). Findings concerning officers' negative experiences of leadership in the SA Army's commitment and support provide support for the notion in literature that effective leaders are core to ensure effective QM.

Officers indicated that poor planning by the SA Army and inadequate placement of personnel (officers) in positions (key) at corps training units (that do not have the required credentials) influenced QM of training adversely. Khan et al. (2019) indicated in this regard that good leaders are required to be knowledgeable. Similarly, Carrington et al. (2019) found that leaders' performance is key during difficult times in organizations; however, the relationship between cognitive abilities and performance at different organisational levels could not be measured, as this was beyond the scope of this research. The latter is particularly a requirement in dynamic environments [such as in the SA Army] to be able to meet the needs of future business and ensure managerial effectiveness. Additionally, it seems that transformation (affirmative action) is experienced as a constraint to ensure effective QM of training in corps training units. The management of the placement of personnel in key positions and promotion of officers created adverse effects on QM efforts. Previous research (Kilonzo and Ikamari, 2015) similarly found that there is a close relationship between affirmative action implementation and the quality-of-service delivery, though within a different context (public service sector). Another finding that highlights the effect on leaders' commitment to QM of training is the involvement of people to the lowest level in the QM of training.

A lack of trust between officers at corps training units and their leaders in the SA Army was experienced due to poor communication, which affected the QM of training negatively. Hall et al.'s (2018) research showed the opposite that when leaders are able to develop trusted relationships with peers and subordinates, it provides a foundation of support for personnel. On the other hand, Kosfeld (2020) found that when there is distrust between leaders and personnel, it may also lead to a self-fulfilling prophecy. The latter opposite finding may be due to the bureaucratic structure and geographical dispersion between different levels in the SA Army system that may have created difficult circumstances for good communication. However, it seems that the SA Army makes use of management systems with high levels of bureaucracy, which creates barriers to ensure effective communication for the successful implementation of QM of training. Nevertheless, bureaucracy has also created lack of trust between officers at corps training units and other officers at the SA Army. In this regard, though within a different context (manufacturing), Almeida et al. (2018), indicated that organizations require management systems with low levels of bureaucracy to ensure the success of QM implementation. Previous leadership research (Neubert et al., 2016) indicated that when servant is present in leadership in high levels of organisational structure, it leads to both job satisfaction and creativity of personnel. However, in the absence of servant leadership, it may have the opposite effect. Regardless, the lack of trust experienced by officers may point out that servant leadership is absent within the high levels of bureaucracy in the SA Army, which led to poor communication, thereby having an adverse effect on the QM of training.

Officers pertinently indicated that poor attitudes of other leaders in corps training units towards QM also affect commitment adversely. However, this may be context specific and further research within other contexts (countries and sectors) is suggested to confirm this finding. Most officers in corps training units B and D also indicated that the lack of support (not providing the required resources) they receive from leaders in the SA Army system creates a negative attitude among officers at corps training units, which affects their commitment adversely. The foundations of QM and its system are continuous improvement, customer focus, responsibility at work, leadership commitment and satisfaction [attitudes commitment] of personnel (Batista et al., 2013). Batista et al's (2013) research in the manufacturing and services sector corroborates the findings in this research [concerning poor attitudes that affect leaders' commitment to QM of training] that when management [SA 
Army] does not support QM practices [at corps training units], it will negatively affect personnel's involvement, job satisfaction and commitment.

These findings indicate the importance of leaders' affective state (attitudes and commitment) to ensure effective implementation of QM in training. Additionally, it seems that a good relationship between leaders at all levels is important for effective QM of training. The selection of the systems theory to test the effect of leaders' attitudes and commitment to $\mathrm{QM}$ of training was appropriate because of the cross-functional practice of QM.

\section{Quality management of training}

\section{Implications for theory and practice}

This research has implications for academic researchers. The findings support the notion that $\mathrm{QM}$ is conceptualised as published guidelines that provide a vision to create styles, frameworks and methodologies for an organisation, necessary to obtain and sustain quality (Meyer et al., 2017). Within the context of the research, the findings also suggested that QM is a crossfunctional practice that emphasises a process-oriented workflow (Weckenmann et al., 2015). Moreover, QM requires all people (to the lowest level) in an organisation to be involved and that it should be managed as part of an organisational system to deal with the dynamic environment in which the SA Army and other organizations may find themselves. Even though academic researchers have investigated leaders' attitudes in relation to commitment, there were limited previous studies that could be located that investigated this qualitatively. The findings indicated that officers' attitudes were affected by aspects of the organisation's system of which leadership form's part. Furthermore, aspects such as lack of resources, inadequate communication and lack of trust adversely affected leaders' attitudes. Bureaucracy was also found to affect leaders' attitudes that, in turn, had an adverse effect on their commitment to QM of training. However, these latter findings may also be context specific, as it seemed that, in this research, lack of trust had a greater influence on officers' attitudes that led to poor commitment to QM of training. In this regard, the implication for academic researchers will be to examine to what extent leaders' ability to establish trust and communicate effectively may be linked to their commitment to QM of training. The latter are behavioural outcomes that academic researchers will also have to increasingly investigate. These are the affective domains (attitudes and commitment) of leadership that academic researchers need to investigate, as also previously alluded to by Vogel et al. (2021), though not only on an individual level, but also on organisational level (because of the system). This would assist the "what" and "how" to address leaders' attitudes and commitment to QM of training in the future.

The research also has practical implications for practitioners. Since organizations budget for large training expenditures each year, it is worthwhile to design processes to assess and improve leaders' commitment to training excellence. Within this context, our findings point to the benefits of gaining awareness of leaders' attitudes to improve and maintain leaders' commitment to QM of training in this sphere. This research showed that most QM problems experienced by officers in corps training units were caused by other leaders from the SA Army, and consequently originated from the larger organisational system. Both lack of resources and lack of trust had an adverse effect on QM of training. However, resources may only influence leaders' attitudes to some extent as the SA Army's budget allocation is provided by government and not officers themselves. Though, lack of trust may have influenced c leaders' affective state more than lack of resources. A lack of transparency and poor communication from senior officers at the SA Army and corps training units may have contributed to this lack of trust. Since the inputs to the QM system were found to be problematic due to a lack of support (resources - human, finances, logistics) obtained, the outputs (goals) of the quality of training were also affected adversely. The findings in this research also indicated that the bureaucratic system created problems (lack of trust - communication) for officers, which adversely affected the implementation of QM of training. Transparency and communication, 
TQM

34,7

even within a bureaucratic system, are important to ensure a relationship of trust between leaders at all levels. Therefore, trust may be more important to ensure commitment of leaders to QM of training than, for example, resources. Creating self-awareness among leaders regarding their relationships with personnel has great potential for contributing to quality management of training. Practically, the development of leaders will require the SA Army and other organizations to be committed to establishing a leader identity to sustain motivation and interest over time. In an organisation such as the SA Army, with high levels of bureaucracy, leaders who adopt and demonstrate servant leadership, may improve the job satisfaction and creativity of their personnel (Neubert et al., 2016). Committed leaders who support personnel effectively are core to ensure high quality training. For QMand HRD practitioners, the findings provide insight and awareness of certain behavioural aspects from the affective domain to address the attitudes of leaders so that their commitment (behaviour) to QM of training may lead to improved organisational performance.

\section{Recommendations}

This research proposes an overarching set of recommendations that focus on the implementation of a revised TQM programme and training and development interventions (employee orientation programmes, leadership development programmes, coaching and mentoring) to increase trust between officers and personnel to improve officers' commitment to QM of training. Leaders should be made aware of this research findings to improve selfawareness. Creating self-awareness among leaders as a recommendation may be useful to act as a precursor to leadership (Lui et al., 2021). Leaders should also demonstrate servant leadership to foster trust among personnel in the SA Army with high levels of bureaucracy (Neubert et al., 2016). These recommendations may contribute towards strengthening the relationship between the corps training unit's quality culture, training and leadership commitment, as suggested by Talib et al. (2011). The importance of these programmes lies in the fact that it is anticipated to improve leaders' affective state to QM of training. Consequently, QM of training should improve.

\section{Conclusion}

This qualitative research explored officers in corps training units' attitudes and commitment to QM of training in the SA Army. The critical role that resources, trust and communication have on leaders' affective state concerning QM of training was highlighted. For the military in particular - and even other organizations in general - greater cognisance of the relationship between leaders and personnel should be taken to ensure that commitment (behaviour) to QM of training has been established. Therefore, determining to what extent frustrations (resources, enthusiasm, passion and resistance to change) adversely affect the attitudes of leaders in relation to their trust in other leaders (officers) to imbue commitment may assist organizations to identify appropriate interventions to ensure the effective implementation of QM of training. This research enhances leaders and HRD practitioners' understanding of leaders' affective state within the context of QM. Further research into the effect of leaders' affective state on QM of training within other contexts should also be conducted.

\section{References}

Almeida, D., Pradhan, N. and Muniz, J. (2018), “Assessment of ISO 9001:2015 implementation factors based on AHP", International Journal of Quality and Reliability Management, Vol. 35 No. 7, pp. 1343-1359, doi: 10.1108/IJQRM-12-2016-0228.

Anderson, V., Fontinha, R. and Robson, F. (2020), Research Methods in Human Resource Management, 4th ed., CIPD, London. 
Aramovich, N.P. and Blankenship, J.R. (2020), "The relative importance of participative versus decisive behaviour in predicting stakeholders' perceptions of leader effectiveness", The Leadership Quarterly, Vol. 31, doi: 10.1016/j.leaqua.2020.101387.

Batista, M., Feijo, A. and Silva, F. (2013), "Quality management and employees' attitudes: an example from certified enterprises", Management Research: The Journal of the Iberoamerican Academy of Management, Vol. 11 No. 3, pp. 260-279, doi: 10.1108/MRJIAM-01-2012-0468.

Boe, O. (2015), "Character in military leaders, officer competency and meeting the unforeseen", paper presented at the 2nd Global Conference on Psychology Research 2014, 28-29 November 2014, Barcelona, University of Barcelona. doi: 10.1016/j.sbspro.2015.05.033 (accessed 23 April 2020).

Boulu-Reshef, B., Holt, C.A., Rodgers, M.S. and Thomas-Hunt, M.C. (2020), "The impact of leader communication on free-riding: an incentivized experiment with empowering and directive styles”, The Leadership Quarterly, Vol. 31, doi: 10.1016/j.leaqua.2019.101351.

Carrington, D.J., Combe, I.A. and Mumford, M.D. (2019), "Cognitive shifts within leader and follower teams: where consensus develops in mental models during an organisational crisis", The Leadership Quarterly, Vol. 30, pp. 335-350, doi: 10.1016/j.leaqua.2018.12.002.

Chen, S.-H. (2012), "The establishment of a quality management system for the higher education industry", Quality and Quantity: International Journal of Methodology, Vol. 46, pp. 1279-1296, doi: 10.1007/s11135-011-9441-1.

Cheong, M., Spain, S.M., Yammarino, F.J. and Yun, S. (2016), “Two faces of empowering leadership: enabling and burdening", The Leadership Quarterly, Vol. 27, pp. 602-616, doi: 10.1016/j.leaqua. 2016.01.006.

Chowdhury, M., Paul, H. and Das, A. (2007), "The impact of top management commitment on total quality management practice: an exploratory study in the Thai garment industry", Global Journal of Flexible Systems Management, Vol. 8 No. 1, pp. 17-29, doi: 10.1007/bf03396517.

Creswell, J.W. and Creswell, J.D. (2018), Research Design: Qualitative, Quantitative and Mixed Methods Approaches, 5th ed., Sage, London. doi: 10.7748/nr.12.1.82.s2.

Ehrhardt, R.D., Freeman, S.J. and Hom, P.W. (2011), "An examination of the relationship between training comprehensiveness and organizational commitment: further exploration of training perceptions and employee attitudes", Human Resource Development Quarterly, Vol. 22, pp. 459489, doi: 10.1002/hrdq.20086.

Eisenkopf, G. (2020), "Words and deeds - experimental evidence on leading-by-example", The Leadership Quarterly, Vol. 31, doi: 10.1016/j.leaqua.2020.1013813.

Els, R.C., Meyer, H.W. and Ellis, S. (2021), "A measurement scale developed to investigate the effect of leaders' perceptions regarding attitudes towards and commitment to quality management of training", International Journal of Training and Development, Vol.00, pp. 1-25, doi: 10.1111/ijtd.12243.

Gildenhuys, C. (2013), "Force composition and design”, South African Army Journal, Vol. 7, pp. 11-17, available at: http://www.army.mil.za/publications/journal/2013_publish/2/SAAJ_7 2013 INNER PRINT.pdf.

Hall, F., Petrossian, B. and Spackman, T. (2018), "I would recommend it to anyone!' Transferring leadership development and evaluating for impact at Skipton Building Society", International Journal of HRD Practice, Policy and Research, Vol. 3 No. 2, pp. 7-22, doi: 10.22324/ijhrdppr.3.111.

Harrison, D.A., Newman, D.A. and Roth, P.L. (2006), "How important are job attitudes? Meta-analytic comparisons of integrative behavioural outcomes and time sequences", Academy of Management Journal, Vol. 49, pp. 305-325, doi: 10.5465/amj.2006.20786077.

Jamaluddin, Z., Razali, A.M. and Mustafa, Z. (2015), "The relationship between quality management practices and organisational performance: a structural equation modelling approach", Paper Presented at the 2nd ISM International Statistical Conference, pp. 494-504. doi: 10.1063/1.4907485.

Javed, S. (2015), "Impact of top management commitment on quality management", International Journal of Scientific and Research Publications, No. 8, pp. 1-5, available at: www.ijsrp.org/ research-paper-0815/ijsrp-p4453.pdf. 
TQM

34,7

$\mathrm{Ju}$, B. (2019), "The roles of the psychology, systems and economic theories in human resource development", European Journal of Training and Development, Vol. 43 Nos 1/2, pp. 132-152, doi: 10.1108/EJTD-02-2018-0020.

Khan, M.N., Malik, S.A. and Janjua, S.Y. (2019), "Total quality management practices and work-related outcomes: a case study of higher education institutions in Pakistan", International Journal of Quality and Reliability Management, Vol. 36 No. 6, pp. 864-874, doi: 10.1108/IJQRM-042018-0097.

Kilonzo, E.M. and Ikamari, L. (2015), "Impact of affirmative action on quality-of-service delivery in the public service sector of Kenya: a comparative case study", Journal of Education and Practice, Vol. 6 No. 3, pp. 113-125, available at: https://files.eric.ed.gov/fulltext/EJ1083851.pdf.

Kirchner, M.J. and Akdere, M. (2014), "Examining leadership development in the U.S. Army within the human resource development context: implications for security and defence strategies", The Korean Journal of Defence Analysis, Vol. 26, pp. 351-369, available at: https://www.researchgate. net/publication/319878330.

Kosfeld, M. (2020), "The role of leaders in inducing and maintaining cooperation: the CC strategy", The Leadership Quarterly, Vol. 31, doi: 10.1016/j.leaqua.2019.04.002.

Luburic, R. (2015), "Quality management principles and benefits of their implementation in central banks", Journal of Central Banking Theory and Practice, Vol. 3, pp. 91-121, doi: 10.1515/jcbtp2015-0013.

Lui, Z., Venkatesh, S., Murphy, S.E. and Riggio, R.E. (2021), "Leader development across the lifespan: a dynamic experiences-grounded approach”, The Leadership Quarterly, Vol. 32, doi: 10.1016/j. leaqua.2020.101382.

Majid, S., Lopez, C., Megicks, P. and Lim, W.M. (2019), "Developing effective social media messages: insights from an exploratory study of industry experts”, Psychology Marketing, Vol. 36 No. 6, pp. 1-14, doi: 10.1002/mar.21196.

Mathew, G.A. and Zacharias, S. (2016), "A conceptual overview on relationship between employee attitude towards training and organizational commitment", presented at the 3rd International HR Conference, October, available at: http://smbs.mgu.ac.in/wp-content/uploads/2017/10/ sibyzac-cv-2017.doc (accessed 19 April 2019).

McCauley, C.D. and Palus, C.J. (2021), "Developing the theory and practice of leadership development: a relational view", The Leadership Quarterly, Vol. 803, doi: 10.1016/j.leaqua.2020.101456.

Meyer, M. (2016), Managing Human Resource Development, LexisNexis, Durban.

Meyer, M., Orpen, M. and Rajaram, S. (2017), Occupationally Directed Education, Training and Development Practices, 3rd ed., LexisNexis, Durban.

Mosadeghrad, A.M. (2015), "Developing and validating a total quality management model for healthcare organisations”, The TQM Journal, Vol. 27 No. 5, pp. 544-564, doi: 10.1108/TQM-042013-0051.

Neubert, M.J., Hunter, E.M. and Tolentino, R.C. (2016), “A servant leader and their stakeholders: when does organizational structure enhance a leader's influence”, The Leadership Quarterly, Vol. 27, pp. 896-910, doi: 10.1016/j.leaqua.2016.05.005.

Nguyen, M.H., Phan, A.C. and Matsui, Y. (2018), "Contribution of quality management practices to sustainability performance of Vietnamese firms", Sustainability, Vol. 10, doi: 10.3390/ su10020375.

Nhlapo, T.M.S. (2010), "The implementation of human resource development strategy for total quality management with the department of correctional services: a focus on Groenpunt management area”, Unpublished master's mini-dissertation, North-West University, Potchefstroom.

Nieuwenhuis, J. (2016), “Analysing qualitative data”, in Maree, K. (Ed.), First Steps in Research, 2nd ed., Van Schaik Publishers, Pretoria, pp. 103-132. 
Porter, L.W., Steers, R.M., Mowday, R.T. and Boulian, P.V. (1974), "Organizational commitment, job satisfaction, and turnover among psychiatric technicians", Journal of Applied Psychology, Vol. 59, pp. 603-609, doi: 10.1037/h0037335.

Shabbir, M., Khalid, M.I., Bakhsh, K., Mohsin, M.N., Rasool, S. and Mohsin, M.S. (2016), "Improving professional development system through quality assurance practices in the universities of Pakistan”, International Education Studies, Vol. 9 No. 1, pp. 141-147, doi: 10.5539/ies.v9n1p141.

Shenge, N.A. (2014), "Training evaluation: process, benefits and issues", Ife Psychologia, Vol. 22 No. 1, pp. 50-58, available at: https://www.coursehero.com/file/22231295/Training-evaluation-Processbenefits-and-issues/.

South African Department of Defence (2016), "Human resource development strategy 2016-2025: renewal and modernisation", Department of Defence (In preparation).

Talib, F. and Rahman, Z. (2015), "Identification and prioritization of barriers to total quality management implementation in service industry", The TQM Journal, Vol. 27 No. 5, pp. 591-615, doi: 10.1108/TQM-11-2013-0122.

Talib, F., Rahman, Z. and Quresh, M.N. (2011), "Prioritising the practices of total quality management: an analytic hierarchy process analysis for the service industries", Total Quality Management and Business Excellence, Vol. 22 No. 12, pp. 1331-1351, doi: 10.1080/14783363.2011.625192.

Thomas, G. (2016), How to Do Your Case Study, 2nd ed., Sage, London.

Tsui, A.S., Zhang, Z., Wang, H., Xin, K.R. and Wu, J.B. (2006), "Unpacking the relationship between CEO leadership behaviour and organizational culture", The Leadership Quarterly, Vol. 17, pp. 113-137, doi: 10.1016/j.leaqua.2005.12.001.

Vogel, B., Reichard, R.J., Batistič and, S. and Černe, M. (2021), “A bibliometric review of the leadership development field: how we got here, where we are, and where we are headed", The Leadership Quarterly, Vol. 803, doi: 10.1016/j.leaqua.2020.101381.

Wallace, D.M., Torres, E.M. and Zaccaro, S.J. (2021), "Just what do you think we are doing? Learning outcomes of leader and leadership development", The Leadership Quarterly, Vol. 32, doi: 10. 1016/j.leaqua.2020.101494.

Weckenmann, A., Akkasoglu, G. and Werner, T. (2015), “Quality management - history and trends", The TQM Journal, Vol. 27 No. 3, pp. 281-293, doi: 10.1108/TQM-11-2013-0125.

Wessels, A. (2013), "South Africa's land forces, 1912-2012", Journal for Contemporary History, Vol. 38 No. 1, pp. 229-254, doi: 10.10520/EJC138880.

West, J. and Cianfrani, C.A. (2014), "Managing the system revision introduces focus on organisational operating conditions", Quality Progress, Vol. 47, pp. 53-56.

Wong, W.L., Mohamed, H.B., Ananthan, S., Liaw, J.O.H. and Inderjit, S. (2018), "Quality management dimensions for sustainable performance in military organisation", International Journal of Business and Management, Vol. 2 No. 1, pp. 38-42, doi: 10.26666/rmp.ijbm.2018.1.7.

\section{Corresponding author}

Renier Christiaan Els can be contacted at: renier.els@nwu.ac.za

For instructions on how to order reprints of this article, please visit our website:

www.emeraldgrouppublishing.com/licensing/reprints.htm

Or contact us for further details: permissions@emeraldinsight.com 